Behavioral/Cognitive

\title{
Amygdala Modulation of Cerebellar Learning
}

\author{
Sean J. Farley, ${ }^{-J a s o n ~ J . ~ R a d l e y, ~ a n d ~} \odot$ John H. Freeman \\ Department of Psychological and Brain Sciences, University of Iowa, Iowa City, Iowa 52242
}

Previous studies showed that amygdala lesions or inactivation slow the acquisition rate of cerebellum-dependent eyeblink conditioning, a type of associative motor learning. The current study was designed to determine the behavioral nature of amygdala-cerebellum interactions, to identify the neural pathways underlying amygdala-cerebellum interactions, and to examine how the amygdala influences cerebellar learning mechanisms in rats. Pharmacological inactivation of the central amygdala $(\mathrm{CeA})$ severely impaired acquisition and retention of eyeblink conditioning, indicating that the amygdala continues to interact with the cerebellum after conditioning is consolidated (Experiment 1). CeA inactivation also substantially reduced stimulus-evoked and learning-related neuronal activity in the cerebellar anterior interpositus nucleus during acquisition and retention of eyeblink conditioning (Experiment 2). A very small proportion of cerebellar neurons responded to the conditioned stimulus (CS) during CeA inactivation. Finally, retrograde and anterograde tracing experiments identified the basilar pontine nucleus at the confluence of outputs from CeA that may support amygdala modulation of CS input to the cerebellum (Experiment 3). Together, these results highlight a role for the CeA in the gating of CS-related input to the cerebellum during motor learning that is maintained even after the conditioned response is well learned.

Key words: amygdala; cerebellum; conditioning; interpositus; learning

\section{Significance Statement}

The current study is the first to demonstrate that the amygdala modulates sensory-evoked and learning-related neuronal activity within the cerebellum during acquisition and retention of associative learning. The findings suggest a model of amygdalacerebellum interactions in which the amygdala gates conditioned stimulus inputs to the cerebellum through a direct projection from the medial central nucleus to the basilar pontine nucleus. Amygdala gating of sensory input to the cerebellum may be an attention-like mechanism that facilitates cerebellar learning. In contrast to previous theories of amygdala-cerebellum interactions, the sensory gating hypothesis posits that the gating mechanism continues to be necessary for retrieval of cerebellar memory after learning is well established.

\section{Introduction}

Memory system interactions play a critical role in complex behavior (Poldrack and Packard, 2003). Interactions between emotional and motor memory systems are particularly important because memory for the emotional significance of stimuli provides essential contextual information for acquisition of motor responses. Memory for the significance of stimuli can also modify the strength and speed of a learned motor response. The early theoretical framework for this type of two-process learning, developed by Mowrer (1947) and elaborated by others (Konorski, 1967; Prokasy, 1987), has been adapted more recently to a neural two-process theory. In the neural two-process theory, the

\footnotetext{
Received Sept. 7, 2015; revised Dec. 28, 2015; accepted Jan. 2, 2016.

Author contributions: S.J.F., J.J.R., and J.H.F. designed research; S.J.F. performed research; S.J.F. and J.J.R. analyzed data; S.J.F., J.J.R., and J.H.F. wrote the paper.

This work was supported by National Institutes of Health Grants NS088567 (J.H.F.) and MH095972 (J.J.R.).

Correspondence should be addressed to John H. Freeman, Department of Psychological and Brain Sciences, University of lowa, lowa City, IA 52242. E-mail: john-freeman@uiowa.edu.

DOI:10.1523/JNEUROSCI.3361-15.2016

Copyright $\odot 2016$ the authors $\quad 0270-6474 / 16 / 362190-12 \$ 15.00 / 0$
}

amygdala-mediated memory system facilitates the cerebellummediated motor memory system during associative learning (Thompson, 1987; Weisz et al., 1992; Mintz and Wang-Ninio, 2001; Lee and Kim, 2004). The main evidence supporting this theory is that lesions or inactivation of the amygdala slow the rate of acquisition of cerebellum-mediated eyeblink conditioning (Lee and Kim, 2004; Blankenship et al., 2005; Burhans and Schreurs, 2008). A crucial part of the neural two-process theory is that the amygdala forms a memory for the emotional significance of the conditioned stimulus (CS), which then facilitates the formation of a second memory in the cerebellum essential for the eyeblink conditioned response (CR).

The neural pathways for an auditory CS and the air puff or periorbital shock unconditioned stimulus (US) are well characterized for eyeblink conditioning (Freeman and Steinmetz, 2011). For an auditory CS, the transynaptic pathway that is necessary and sufficient for eyeblink conditioning includes the auditory brainstem nuclei, medial auditory thalamus, and the lateral aspect of the basilar pontine nucleus (BPN; Halverson and Freeman, 2006, 2010a; Campolattaro et al., 2007; Freeman et al., 2007; 
Halverson et al., 2008, 2015). The BPN gives rise to the mossy fiber projection into the cerebellar cortex and deep nuclei (Brodal and Bjaalie, 1992; Steinmetz and Sengelaub, 1992; Shinoda et al., 2000). The base of the primary fissure in the cerebellar cortex and the anterior interpositus nucleus (AIN) are the essential sites of plasticity for eyeblink conditioning in rodents (Steinmetz and Freeman, 2014). The amygdala is thought to facilitate cerebellar learning through projections to the CS pathway, thereby increasing CS salience (Taub and Mintz, 2010; Siegel et al., 2015). However, the effects of altering amygdala activity on cerebellar function have not been examined directly.

The current study was designed to examine how the amygdala influences cerebellar learning mechanisms. We first used pharmacological inactivation of the central amygdala (CeA) during acquisition and retention of eyeblink conditioning (Experiment 1). CeA inactivation was then done while recording neuronal activity from the AIN from multiple tetrodes during acquisition and retention of eyeblink conditioning (Experiment 2). The final experiment used anterograde and retrograde axonal tracers to investigate projections from the CeA to the CS pathway (Experiment 3). The results are inconsistent with the two-process theory, indicating that the CeA gates CS input to the cerebellum during motor learning and continues to serve this function after the motor CR is well learned.

\section{Materials and Methods}

Subjects

Subjects were 71 male Long-Evans rats $(250-300 \mathrm{~g})$ that were $\sim 3$ months of age at the beginning of the study. Thirty-six rats were used for Experiment 1, 15 for in vivo neurophysiology in Experiment 2, and 20 for axonal tract tracing in Experiment 3. Rats were housed singly in Spence Laboratories of Psychology at the University of Iowa on a $12 \mathrm{~h}$ light/dark cycle with food and water available ad libitum. All experimental procedures were approved by the Institutional Animal Care and Use Committee.

\section{Surgery}

For all experiments, rats were anesthetized with $2-3 \%$ isoflurane and administered an analgesic subcutaneously (Ketofen, $5 \mathrm{mg} / \mathrm{kg}$ ). All stereotaxic coordinates are relative to bregma. For amygdala infusion and pressure injection surgeries, the coordinates used were as follows: anteroposterior, $-2.4 \mathrm{~mm}$; mediolateral, $\pm 4.2 \mathrm{~mm}$; dorsoventral, $-7.1 \mathrm{~mm}$ (Paxinos and Watson, 2007). The skull was exposed, and $0.5 \mathrm{~mm}$ holes were drilled bilaterally over the CeA. Guide cannulae (27 gauge) were lowered to within $1 \mathrm{~mm}$ of the dorsal border of the CeA and were sealed with a 32-gauge stylet. Rats were then fitted with eyelid EMG electrodes and a bipolar electrode just caudal to the eye (to deliver the US), as described previously (Freeman and Nicholson, 1999).

In Experiment 2, microdrives were implanted stereotaxically over the AIN ipsilateral to the trained eye (anteroposterior, $-11.1 \mathrm{~mm}$; mediolateral, $2.7 \mathrm{~mm}$ ). A small craniotomy was made with a $1.0 \mathrm{~mm}$ hole saw drill bit. The dura mater was punctured carefully and removed to allow for unencumbered passage of tetrode wires into the brain. The bundle/ brain interface was sealed with sterile silicon (KwikSil; World Precision Instruments). The microdrive was grounded with a skull screw, and its base was secured to the rat with bone cement. Tetrode drivers were initially lowered $1.5 \mathrm{~mm}$ during surgery. Drivers were subsequently lowered to the target over a 3-4 d period taking note of neuronal landmarks, such as the dense layer of Purkinje cells and cerebellar white matter while descending to deep cerebellar nuclei.

In Experiment 3, we surveyed putative anatomical substrates that may account for the capacity of CeA to modulate cerebellar learning. This issue was examined in the context of anatomical circuitry relating to the pons, because these cell groups are known to serve as critical relays for descending CS-related information en route to the cerebellum and issues direct projections to the dentate and AIN (Brodal and Bjaalie, 1992; Steinmetz and Sengelaub, 1992; Tracy et al., 1998; Campolattaro and
Freeman, 2008). One group of rats received unilateral pressure injections of $10 \%$ biotinylated dextran amine (BDA) delivered in volumes of $100 \mathrm{nl}$ via micropipettes (10-25 $\mu \mathrm{m}$, inner diameter) for anterograde labeling of CeA neurons. A different group of rats received unilateral pressure injections of $100 \mathrm{nl}$ of 2\% Fluoro-Gold (FG; Flourochrome; Schmued and Fallon, 1986) into the BPN (anteroposterior, $-7.68 \mathrm{~mm}$; mediolateral, $1.20 \mathrm{~mm}$; dorsoventral, $-9.90 \mathrm{~mm}$ from dura) for the identification of candidate cell groups inclusive of, or that may be intermediary to, outputs from the CeA.

\section{Conditioning apparatus}

Conditioning chambers $(12 \times 11 \times 10$ inches $)$ were housed within sound-attenuated boxes that were ventilated with small exhaust fans that also provided audible background noise. One wall of the chamber was fitted with speakers for the tone CS. An EMG and bipolar electrode tether passed through a commutator and were connected to a direct current amplifier and a stimulus isolator, respectively. The amplified EMG was filtered $(0.5-5.0 \mathrm{kHz})$ and integrated before being digitized by a desktop computer. The stimulus isolator was also connected to the computer that specified the timing of stimulation events (CS and US). All surfaces of the conditioning chamber were wiped with $70 \%$ ethanol before the beginning of each session.

\section{Eyeblink conditioning}

Figure $1 A$ shows the onsets and offsets of the stimuli used in delay eyeblink conditioning ( $\mathrm{dEBC})$. The sampling window for each trial was 1000 $\mathrm{ms}$, consisting of a $300 \mathrm{~ms}$ baseline period, $400 \mathrm{~ms}$ CS period, $25 \mathrm{~ms}$ US period, and $275 \mathrm{~ms}$ post-US period. The CS was an $85 \mathrm{~dB}, 2.0 \mathrm{kHz}$ pure tone. The mean intertrial interval was $30 \pm 10 \mathrm{~s}$. Each session consisted of 10 10-trial blocks including nine paired CS-US trials and one CS-alone trial. At least $30 \mathrm{~min}$ before each of the first five sessions, $0.2 \mu \mathrm{l}$ of $2.0 \mathrm{~mm}$ muscimol $\left(\mathrm{GABA}_{\mathrm{A}}\right.$ agonist) or $0.2 \mu \mathrm{l}$ of $0.1 \mathrm{~m}$ PBS $(0.6 \mu \mathrm{l} / \mathrm{h})$ was infused into the CeA bilaterally (Fig. $1 B$ ). Bilateral infusions were used because pilot experiments found that unilateral CeA inactivation did not impair dEBC. It is not clear why unilateral infusions were ineffective, but it might be that amygdala inputs to the pontine nuclei (ipsilateral; see Experiment 3) activate neurons that project to the contralateral PN and/or ipsilateral cerebellar cortex. Custom-built 32 gauge infusion cannulae were lowered into the guide cannula and extended $1.0 \mathrm{~mm}$ ventrally beyond its tip. Infusion cannulae were removed $2 \mathrm{~min}$ after the end of the infusion. Pre-session infusions ended starting with session 6, and training continued until reaching a criterion of two consecutive sessions of $80 \%$ CRs or greater. Rats from both groups were then given two retention sessions with infusions of PBS or muscimol in a counterbalanced order. Because ear bars were used during surgery, a general assessment of hearing was conducted before the first training session in which the experimenter produced noises such as a whistle or snap of the fingers to generate behavioral orientating responses, eyelid EMG activity, and, in Experiment 2, changes in multiunit activity.

\section{Behavioral data collection and analysis}

Integrated EMG activity for each trial was analyzed with a MATLABbased application. CRs were defined as EMG activity that exceeded a threshold of 0.4 units (amplified and integrated units) above the baseline mean during the CS period, $80 \mathrm{~ms}$ after its onset. EMG activity that exceeded the threshold during the first $80 \mathrm{~ms}$ of the CS period was defined as a startle response. CR amplitude was measured from the mean of the pre-CS activity. Unconditioned responses (URs) were defined as activity that crossed the threshold after the offset of the US. Any trial in which the baseline signal crossed threshold was removed from analysis. Behavioral measures were analyzed with $t$ tests, repeated-measures (RM) ANOVA, and Tukey's HSD post hoc tests, when appropriate. The $\alpha$ level for all statistical tests was 0.05 . All reported behavior data were from both paired and unpaired trials.

\section{Neuronal data collection and analysis}

A 32-channel tetrode microdrive was custom fabricated and consisted of eight independently moving recording tetrodes and one reference tetrode. Tetrodes were fabricated by twisting four strands of $12.7-\mu \mathrm{m}$ diameter nichrome wire (Kanthal) into one bundle. Heat was applied to 
A

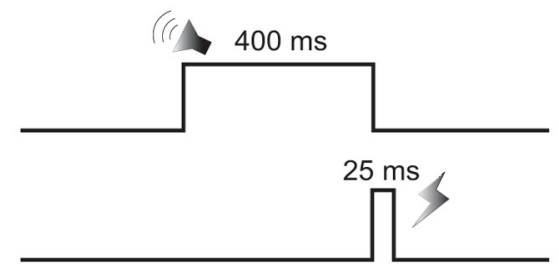

B

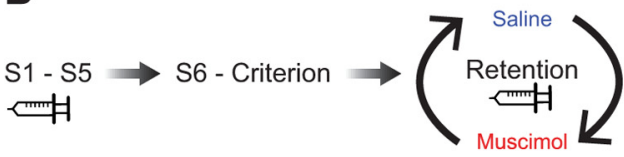

C

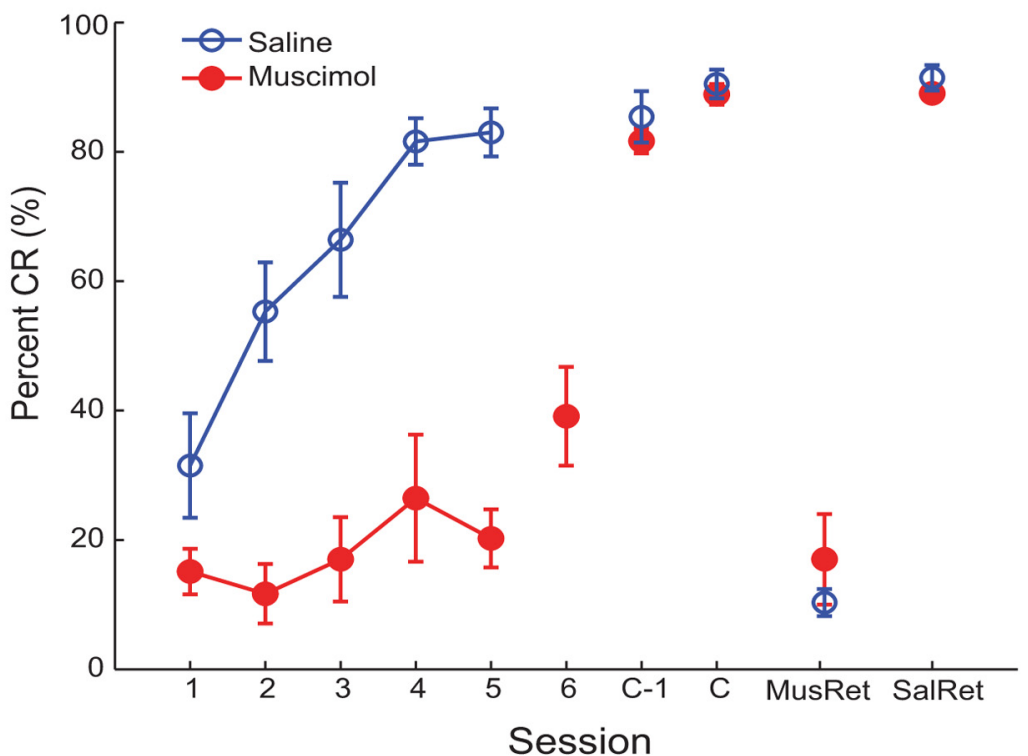

D

Session 1
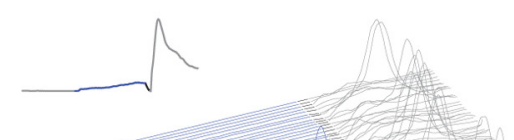

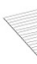
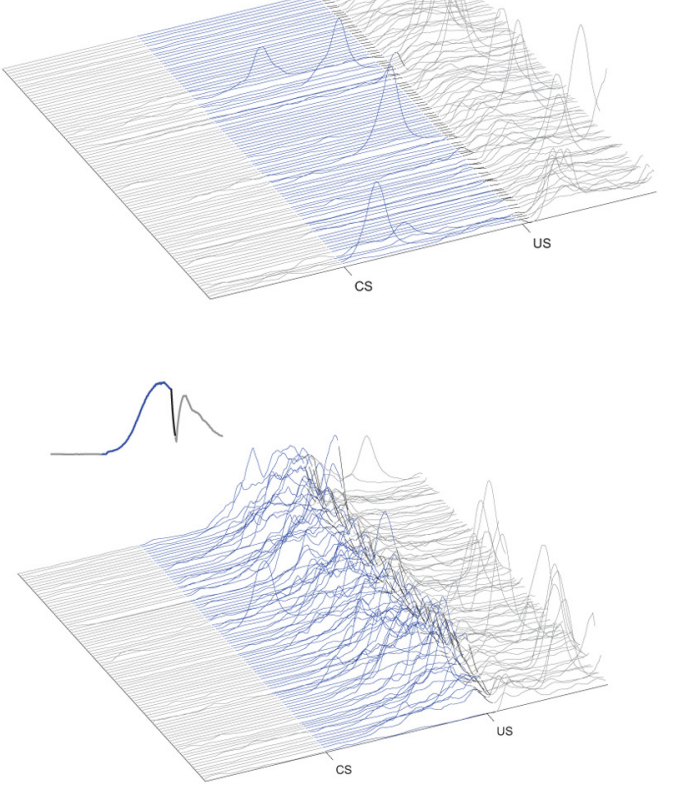

Session 5

Retention

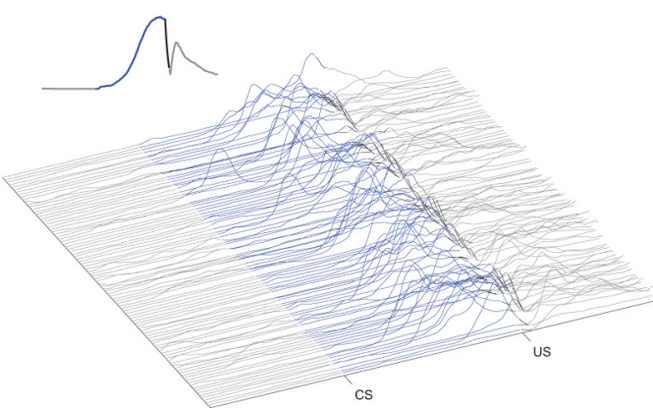

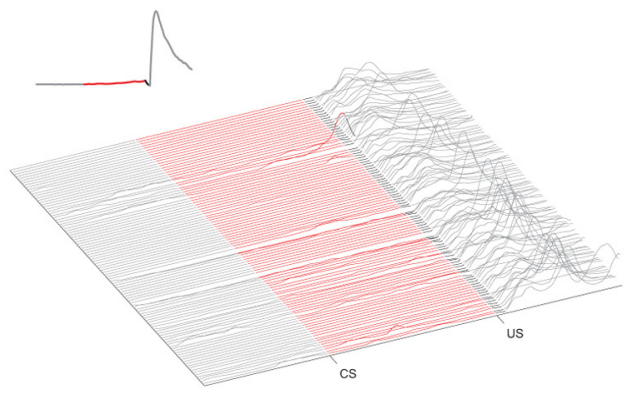
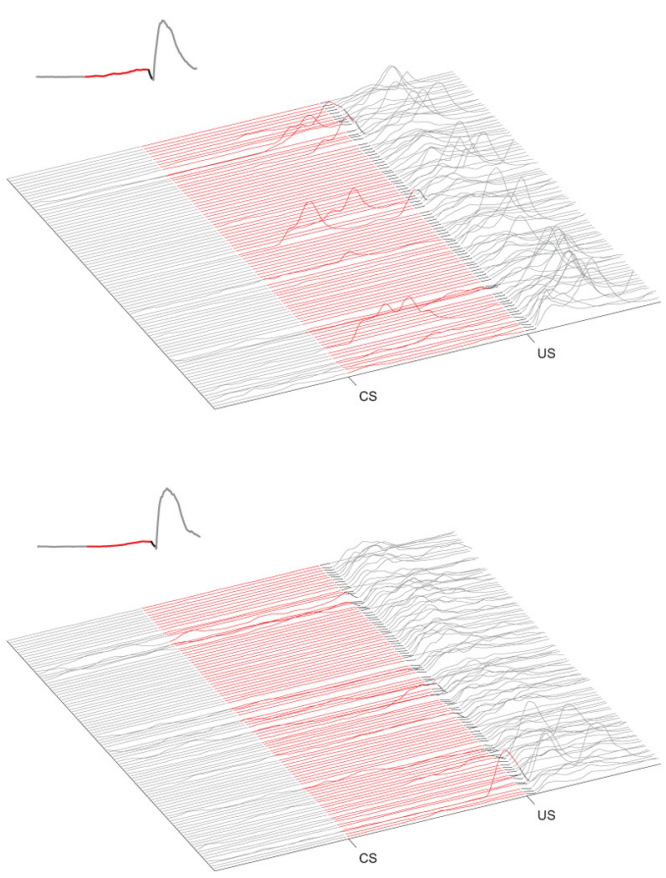
the wire bundle (tetrode) to enhance rigidity. The impedance of the tetrode tips was lowered to $250-350 \mathrm{k} \Omega$ by electroplating in a gold noncyanide solution (SIFCO) at $1.0 \mathrm{kHz}$. Once training began, tetrodes were lowered to increase the quality of recording as necessary but no more than $40 \mu \mathrm{m}$ on any single day. Rats were partially restrained by hand while tetrodes were lowered, followed by a 10-20 min waiting period before the start of a training session.

During eyeblink conditioning sessions, neuronal recordings were sampled at $32.0 \mathrm{kHz}$ (Neuralynx Digital SX), with a bandpass filter set to $0.6-6.0 \mathrm{kHz}$. A 24 bit analog-to-digital converter provided ample signal resolution combined with low tetrode impedance such that signal amplification was not required. Neuronal signals were fed through a preamplifier head stage at unity gain to a motorized commutator, which allowed freely moving behavior. A waveform on one channel exceeding a peak amplitude threshold triggered data collection on all tetrode channels. Depths of tetrodes during training were only adjusted if spikes were not detected. Offline cluster cutting was initially done with Klusta-Kwik (Harris et al., 2000). Manual spike sorting was done with interactive spike sorting MATLAB-based software (MClust version 3.5).

Analyses were done with custom scripts in MATLAB and NexScript (NeuroExplorer). Statistical analyses were done in SPSS. Interpositus unit activity was time locked to stimuli and analyzed with peristimulus histograms. The baseline and CS and US periods were divided into $10 \mathrm{~ms}$ bins (Ng and Freeman, 2012). Neural activity in each CS period bin was normalized to the baseline activity for each unit. A RM-ANOVA was used to assess neural activity differences in bins across infusion treatments and sessions. Repeated-measure analyses for neuronal data were done with the Greenhouse-Geisser correction unless stated otherwise. In a separate analysis, the baseline and CS period were divided into $100 \mathrm{~ms}$ bins. Average firing rates were converted into $z$ scores and normalized to baseline activity with a confidence interval of $95 \%$. The proportions of responsive units between infusion treatments were compared using a $\chi^{2}$ analysis.

\section{Histological and tissue processing}

Experiments 1 and 2. After the end of training, rats were anesthetized deeply with sodium pentobarbital and perfused with $0.1 \mathrm{~m}$ PBS and $10 \%$ formalin. Brains were extracted and postfixed overnight before being cryoprotected in $30 \%$ sucrose/Formalin for $48-72 \mathrm{~h}$. After sectioning at $50 \mu \mathrm{m}$, coronal slices were mounted on glass slides and stained with thionin. Bilateral cannula placement to the CeA and interpositus tetrode placement was then verified with bright-field microscopy.

Experiment 3. Rats used for anatomical tracing experiments were anesthetized deeply with sodium pentobarbital and perfused with $0.1 \mathrm{M}$ PBS and ice-cold $4 \%$ paraformaldehyde at a flow rate of $60 \mathrm{ml} / \mathrm{min}$. Brains were removed, postfixed overnight in the same fixative, and cryoprotected in $20 \%$ sucrose in $0.02 \mathrm{M}$ potassium phosphate buffer for $24 \mathrm{~h}$ at $4^{\circ} \mathrm{C}$. In preparations bearing BDA tracer injections in $\mathrm{CeA}$, the entire brain was sectioned using a freezing microtome, collected into five onein-five series of $30-\mu \mathrm{m}$-thick coronal sections in cryoprotectant solution, and stored at $-20^{\circ} \mathrm{C}$ until histochemical processing for visualization and analysis of axonal terminal fields. For tissue containing retrograde labeling of BPN afferents, brains were sectioned at $50 \mu \mathrm{m}$, mounted onto glass slides, and coverslipped using Vectashield H-1000 (Vector Laboratories).

$\leftarrow$

Figure 1. Acquisition of $\mathrm{dEBC} . A$, Diagram of the delay conditioning paradigm, specifying the onset and offset of the stimuli. $\boldsymbol{B}$, Diagram of the experimental design. Saline or muscimol infusions into the CeA occurred during sessions (S) $1-5$ and at retention. Both groups received saline and muscimol retention sessions, with the order of infusions counterbalanced. $C$, Mean percentage of CRs $\pm S E$ across training sessions. Amygdala inactivation resulted in a severe impairment. Session 6 is shown for the rats that received muscimol during sessions $1-5$ to demonstrate the absence of savings. $(-1$, Session before criterion (2 consecutive sessions $>$ $80 \%$ (R) was reached. C, Session criterion was reached. MusRet, Muscimol retention; SalRet, saline retention. $\boldsymbol{D}$, Waterfall plots of eyeblink topography from representative cases from sessions 1 and 5 and retention. CS period of plots are colored to represent the type of infusion for that session. Blue, Saline; red, muscimol. Top left inset on each plot is the average eyeblink across all animals for the particular session.
Histochemistry. BDA localization was performed in free-floating tissue sections using an avidin-biotin peroxidase protocol (Sawchenko et al., 1990). Sections were first incubated in $0.3 \%$ hydrogen peroxide to neutralize endogenous peroxidase activity and permeabilized by treatment in PBS containing $0.3 \%$ Triton X-100. After a $1 \mathrm{~h}$ incubation using Vectastain Elite reagents (Vector Laboratories), the reaction product was developed using a nickel-enhanced glucose oxidase method (Shu et al., 1988). A separate series of sections were also prepared for BDA localization using fluorescence labeling. This involved incubating sections overnight in the streptavidin-fluorophore conjugate Alexa Fluor 568 (Life Technologies) at a concentration of $1 \mu \mathrm{g} / \mathrm{ml}$.

\section{Results \\ Experiment 1: inactivation of the CeA during eyeblink conditioning}

Eyeblink conditioning

Bilateral muscimol infusions into the CeA severely impaired acquisition of eyeblink conditioning. After the cessation of muscimol infusions, the rats showed no evidence of savings, indicating that the deficit in acquisition was caused by a learning impairment and not by impaired expression. Furthermore, the acquisition rate after cessation in muscimol infusions was no different from the saline-infused rats $(3.6 \pm 1.6$ vs $4.0 \pm 1.2$ sessions $)$. However, associative learning can also be assessed by examining the difference in CR percentage between paired and unpaired groups. Unpaired controls were not run in this experiment, but previous studies using these methods have shown unpaired levels of responding in rats that range from 0 to $12 \%$ CRs (Kleim et al., 2002; Campolattaro and Freeman, 2009). Thus, the muscimol group showed a higher percentage of CRs during Sessions 1-5 than typically seen in unpaired groups, suggesting that they developed a small amount of associative learning during Sessions 1-5.

After reaching the acquisition criterion, rats from both acquisition groups were severely impaired during retention tests when muscimol was infused into the CeA. Figure $1 C$ shows the percentage of CRs for the initial infusion sessions, criterion sessions (R-2 and R-1), and retention sessions. An RM-ANOVA on the CR percentage data for the first five sessions identified a session $X$ group interaction $\left(F_{(4,68)}=4.81, p=0.002\right)$. Post hoc tests revealed that significant group differences in CR percentage began in the second session of conditioning and continued for the remainder of the initial infusion sessions. An independent $t$ test found no difference between the CR percentage during session 6 in rats that had received muscimol infusions during sessions 1-5 versus session 1 of the saline group, indicating the absence of savings in the muscimol group. Both groups of rats reached asymptotic learning before the retention sessions. Regardless of the initial infusion treatment, each group was affected equally by muscimol during retention. A paired samples $t$ test of the CR percentage data during retention sessions (saline vs muscimol, within subjects) revealed a significant reduction in CR percentage with muscimol relative to saline $\left(t_{(18)}=32.01, p<0.0001\right)$.

Additional metrics of eyeblink topography were analyzed, including the percentage of startle responses, amplitude of the CR, $\mathrm{CR}$ onset latency, and peak latency. Example eyeblink responses from individual cases for sessions 1, 5, and retention are displayed in Figure $1 D$. An RM-ANOVA revealed no statistical differences in the percentage of startle responses. However, a group $\times$ session interaction was found for the CR amplitude data $\left(F_{(4,68)}=\right.$ 4.01, $p=0.012$ ). Additional analysis for the retention sessions revealed differences in $\mathrm{CR}$ amplitude based on infusion $\left(t_{(18)}=\right.$ 6.38, $p<0.0001$ ). There were no differences observed in CR onset latency or CR peak latency during acquisition or retention. 
Amygdala inactivation did not affect any measures of the UR (amplitude, peak latency, or area).

\section{Cannula placement}

Cannula placements for Experiments 1 and 2 are shown in Figure 2. Behavioral data from 19 of the original 36 rats in Experiment 1 was analyzed. The remaining rats were removed from analysis because at least one of the cannulae missed the CeA.

\section{Spread of inactivation}

The missed cannula placements were within $1.0 \mathrm{~mm}$ of the $\mathrm{CeA}$, and the rats with missed cannulae showed very good retention during the muscimol test, averaging 74\% CRs. Moreover, two of the rats with accurate cannula placements were given an additional retention test with a lower concentration of muscimol ( 0.876 $\mathrm{mM})$, and these rats showed a retention deficit equivalent to the deficit with the higher concentration used in the rest of the experiments $(2.0 \mathrm{~mm})$. Last, the infusion volume was very small $(0.2 \mu \mathrm{l})$ and therefore could not have spread much beyond the CeA in rats with accurate cannula placements. These assessments of the spread of muscimol indicate that the inactivation effects were localized to the CeA and could not have inactivated the subcortical auditory structures necessary for dEBC (Freeman and Steinmetz, 2011).

\section{Experiment 2: inactivation of the CeA while recording cerebellar neuronal activity}

Eyeblink conditioning

Similar to Experiment 1, rats with bilateral CeA inactivation showed a severe impairment compared with controls. A group $\times$ session interaction during acquisition sessions was identified $\left(F_{(4,28)}=21.2\right.$, $p<0.0001$ ), which was caused by a higher CR percentage in the control group during sessions $2-5$. After criterion was reached, retention was impaired by muscimol infusions relative to the saline infusions $\left(t_{(8)}=28.33, p<0.0001\right)$. No other eyeblink characteristics between these groups differed. Therefore, the behavioral results in Experiment 2 replicated the behavioral results in Experiment 1.

\section{Cannula and tetrode placement}

Single-unit analysis was done for 366 AIN neurons recorded from nine rats. Recordings of putative neurons were kept for analysis if their tetrode location was verified in the AIN (Fig. 3). Reference tetrodes were placed in cerebellar white matter ventral to the cerebellar cortex and dorsal to the interpositus nucleus. Tetrodes that were ventrally $(n=6)$ or dorsally $(n=3)$ located with respect to the AIN were removed from analysis. Six of the 15 rats were removed because of cannula misplacement or loss of the head stage.

\section{Neuronal activity during acquisition}

Firing rate, L-ratio, isolation distance, and interspike interval profiles were all considered when assessing cluster quality of a putative neuron. AIN neurons were tonically active with an average firing rate of $32.6 \pm 2.7 \mathrm{~Hz}$, and the average spontaneous firing rat did not differ between groups after infusions (saline group mean, $32.53 \pm 2.0 \mathrm{~Hz}$; muscimol group mean, $32.95 \pm 1.02 \mathrm{~Hz}$ ). L-ratio and isolation distance are metrics of cluster separation from nearby noise spikes (Schmitzer-Torbert et al., 2005). The mean L-ratio (muscimol group, 0.82; saline group, 0.98) and mean isolation distance (muscimol group, 13.1; saline group, 15.6) did not differ between groups. Examples of single-neuron firing from both groups in Figure 4 show learning-related increases in firing with acquisition in the saline rats that is absent in muscimol rats.

The proportion of neurons with firing rates significantly higher during the CS relative to the pre-CS period was greater in the saline group than in the muscimol group during all of the infusion sessions (sessions 1-5; Fig. 5). This group difference was found for each of the $100 \mathrm{~ms}$ CS intervals. After training without infusions until reaching the learning criterion, the two groups did not differ in the proportion of neurons that were responsive to the CS (Fig. 5). Significant differences were found within subjects for the retention tests, in which the proportion of CS-responsive neurons was greater during the saline retention test $(p<0.001)$ relative to the muscimol retention test $(p<0.001)$.

Neuronal activity was normalized to the pre-CS baseline period to examine group differences in the magnitude of neuronal population firing during learning (sessions 1, 5, and criterion) and during retention tests (saline vs muscimol). Normalized activity during the CS differed between groups across $10 \mathrm{~ms}$ time bins (bin $\times$ group interaction $)$ as early as session $1\left(F_{(12.56,1206.4)}=3.58, p<0.001\right.$; Fig. $6 A)$. Post hoc tests identified differences during the initial period of the CS (bins 3-8, $p<0.05$ ). These differences reflected a neuronal response to the onset of the CS in the saline group that was absent in the muscimol group.

Neuronal activity in session 1 was then divided into 10-trial blocks to further analyze how early group differences in CS-onset 


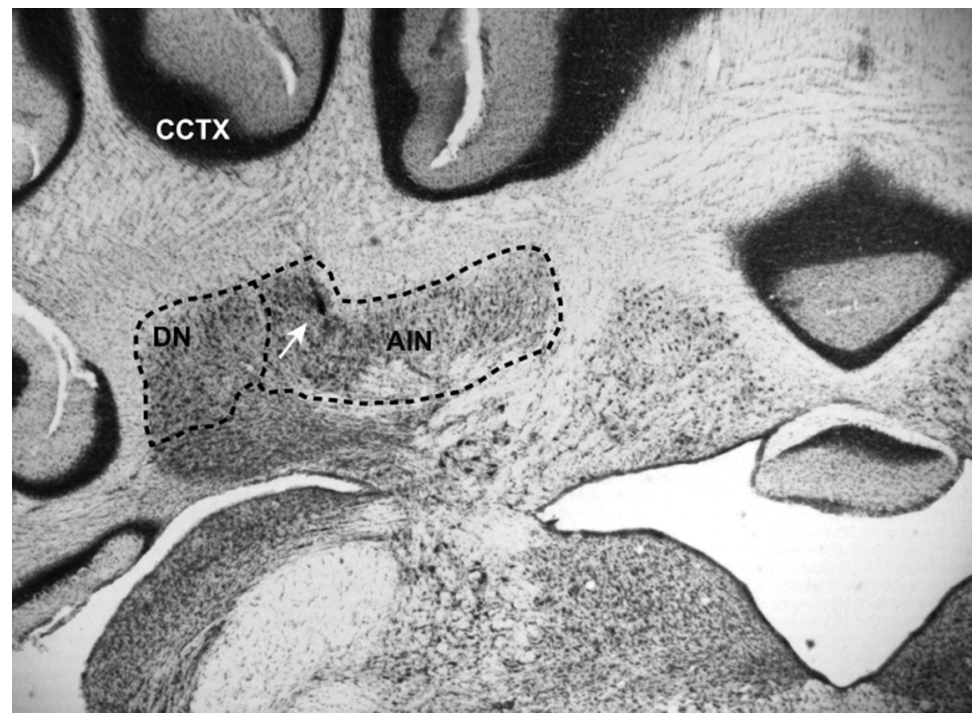

Figure 3. Thionin-stained coronal section of the cerebellum showing a tetrode marking (white arrow) in the lateral portion of the AIN. CCTX, Cerebellar cortex; DN, dentate nucleus.

responses were evident within the first session (Fig. 7). A group (saline vs muscimol) $\times$ block $(1-10) \times$ bin $(1-40)$ analysis revealed no interaction; however, a main effect of group was found $\left(F_{(1,95)}=14.1, p<0.001\right)$. Additional analysis of block 1 (trials $1-10)$ revealed a main effect of group $\left(F_{(1,96)}=4.40, p=0.04\right)$. These subanalyses of group differences in the magnitude of neuronal firing during the CS in the first session suggest that sensory responses to the CS in the cerebellum were suppressed by inactivation of the CeA before learning started. However, the shortest latency responses to the CS (bins 1-3) during the first block did not differ between groups, indicating that the cerebellum was receiving sensory input in the inactivation group but that input was not sustained throughout the CS. The saline group then shows potentiation of the short-latency response in some of the subsequent blocks.

The magnitude of neuronal responses to the CS also differed between groups after learning was well established in the saline group on session 5 (Fig. $6 B$ ). There was a bin $\times$ group interaction $\left(F_{(7.5,494.7)}=12.6, p<0.001\right)$ that was attributable to greater firing in the saline group relative to the muscimol group throughout the CS (bins 3-9, 19-20, and 23-40). The substantial group difference in neuronal firing during session 5 parallels the severe impairment in CR percentage (Fig. 1C) and amplitude.

Neuronal activity from session 1 of the saline group and session 6 of the muscimol group (Fig. $6 C$ ) was compared to examine whether there was neuronal savings in the muscimol group. Neuronal savings would be evident if neuronal activity during the CS was higher in the muscimol group during the first session without muscimol infusions (session 6) relative to the first session in the saline group. A group (saline session 1 vs muscimol session 6$) \times$ bin $(1-40) \mathrm{RM}$ ANOVA revealed a bin $\times$ group interaction $\left(F_{(12.3,753.1)}=3.5, p<\right.$ 0.001 ), with greater activity in the saline group during session 1 early in the CS period (bins 3-6). Thus, there was no evidence of neuronal savings in the muscimol group.

Neuronal activity from each rat's behavioral criterion session was then analyzed with a group $\times$ bin RM-ANOVA. There were no group differences in neuronal activity during the criterion session, indicating that repeated muscimol inactivation during acquisition sessions did not impair the subsequent development of learning-related plasticity in the cerebellum in the absence of infusions (Fig. 6D).

\section{Neuronal activity during retention}

Normalized activity was compared for the saline and muscimol retention sessions in both groups. Because the neuronal populations recorded in the two retention sessions differed within groups, separate RM-ANOVAs were done for the saline and muscimol retention sessions, with the original training condition (saline vs muscimol) as the grouping factor. During both the muscimol and saline retention sessions, neuronal firing during the CS differed between groups (muscimol, $F_{(16.3,996.8)}=3.92, p<0.001$; saline, $\left.F_{(9.4,525.4)}=3.82, p<0.001\right)$. Post hoc tests indicated that the group trained with saline during sessions $1-5$ had greater neuronal firing in the early portion of the CS than the group given muscimol during sessions 1-5 in the saline (bins 3-6 and 10) and muscimol (bins $3-8$ ) retention sessions (Fig. 6E,F). No group differences were found for the second half of the CS period, in which both groups showed robust neuronal responses during the saline retention session. These results indicate that muscimol inactivation of the CeA during initial training (sessions 1-5) resulted in weaker short-latency CS-evoked activity during retention tests (Fig. $6 F$ ), although the rats in both groups had learned to the $80 \%$ criterion.

\section{Experiment 3: anatomical substrates of CeA modulation of cerebellar learning}

Neuroanatomical tracing experiments were performed to investigate the efferent connections from CeA in relation to cerebellar eyeblink conditioning circuitry. In one group of rats $(n=8)$, pressure injections of the anterograde tracer BDA were placed into the $\mathrm{CeA}$, and histochemical visualization of transported BDA was evaluated principally in the descending pathway terminating in mesencephalic and pontine regions. The size and placements of BDA were designed to balance the need for producing reliable and dense labeling of axonal and terminal elements with limiting any confounding labeling that might result from BDA diffusion to adjacent-lying structures (Fig. $8 A, B$ ). The descending trajectory of BDA-labeled elements originating in the $\mathrm{CeA}$ were observed to be almost exclusively ipsilateral and mostly conformed to previous descriptions of the ventral amygdalofugal pathway (Hopkins, 1975; Hopkins and Holstege, 1978; Krettek and Price, 1978; Price and Amaral, 1981; Mihailoff, 1995). These caudally projecting axons were followed from the subthalamic nucleus, between the lateral aspect of the substantia nigra par compacta and red nucleus, and further through the mesencephalic reticular formation. At the pontine level, a small contingent of labeled fibers strayed off ventrolaterally toward BPN, making an array of labeled varicosities and terminal ramifications that were most pronounced in lateral aspects (Fig. 8C). In contrast, no appreciable labeling of axonal elements was observed in the inferior olive, facial motor nucleus, and trigeminal nuclei.

In the caudal diencephalon, the trajectory of labeled fibers traversed immediately subjacent to the medial subdivision of the medial geniculate and posterior intralaminar nuclei (MGm/ 

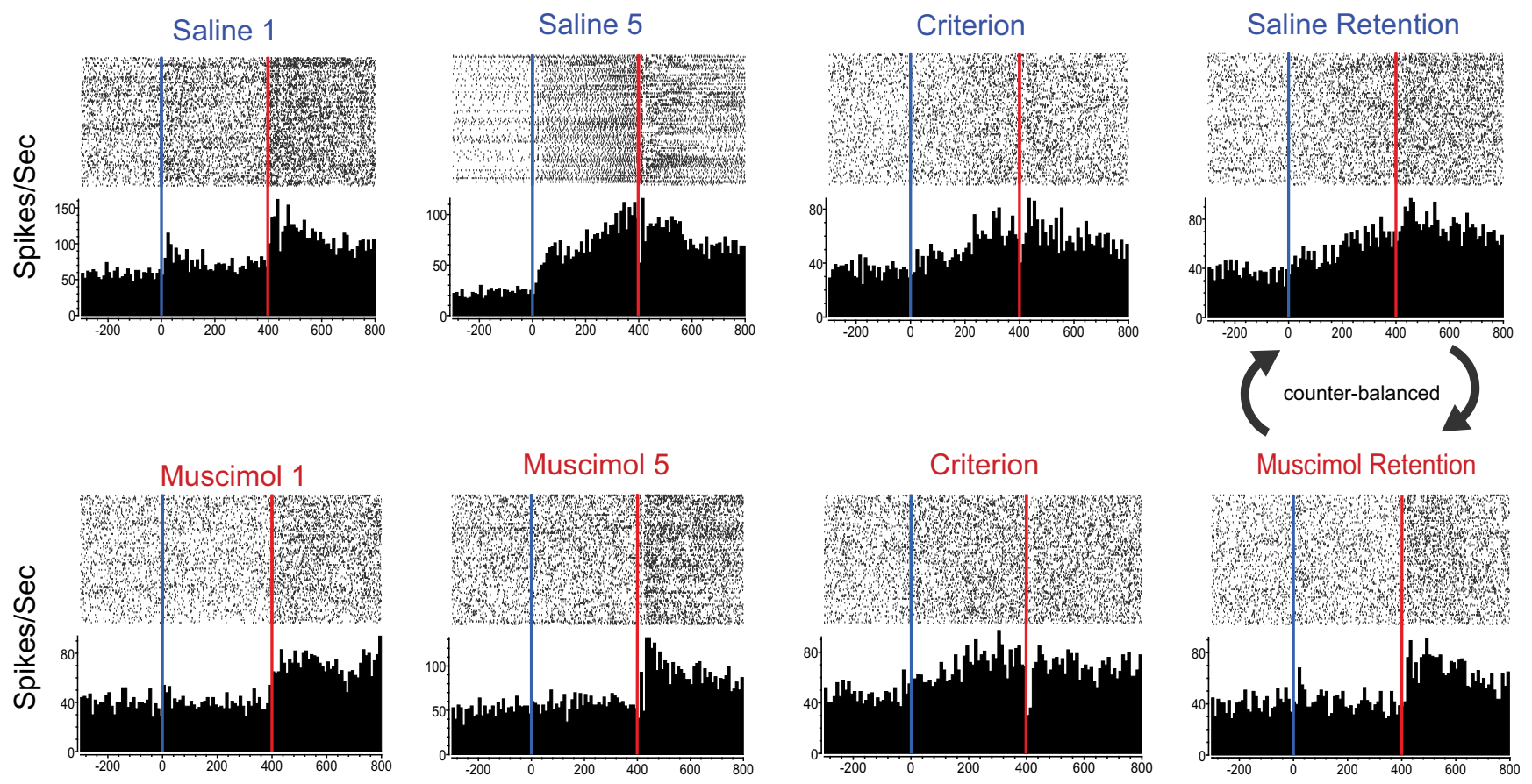

Time (ms)

Figure 4. Representative examples of single-neuron recordings from the cerebellar AIN during eyeblink conditioning. Blue line, CS onset; red line, US onset. Increases in firing rate during the CS were absent in muscimol rats during sessions $1-5$ but were acquired, along with the CR, after cessation of muscimol infusions (Criterion). CeA inactivation during retention in both groups (Muscimol Retention) abolished the learning-related activity, but learning-related activity was retained after saline infusions (Saline Retention). The order of retention sessions with saline and muscimol was counterbalanced within groups.

PIN), raising the possibility that the CeA might provide a collateral projection to the auditory thalamus. Careful examination revealed a sparse labeling of fibers with varicosities and a scattering of terminals within the MGm/PIN, but aperiodic labeling of somata were also noted, which is consistent with reports that anterograde tracing with (even with high molecular weight) dextrans is capable of producing occasional spurious retrograde labeling (for review, see Reiner et al., 2000). That efferents from the acoustic thalamus are known to densely innervate multiple amygdaloid subdivisions, including the CeA (Ottersen and BenAri, 1979; LeDoux et al., 1985; cf. LeDoux et al., 1990) coupled with the lack of a clear precedent for a CeA $\rightarrow$ acoustic thalamic relay (Hopkins, 1975; Hopkins and Holstege, 1978; Krettek and Price, 1978; Price and Amaral, 1981; cf. Shammah-Lagnado et al., 1996), served as additional caveats against interpreting a CeA $\rightarrow$ auditory thalamic relay from these data.

Because BPN represents a final common pathway for relaying CS-related information to the cerebellum during eyeblink conditioning (Steinmetz et al., 1987; Halverson and Freeman, 2010a,b), a second set of tracing experiments using the retrograde tracer FG were performed to confirm that the CeA projects to the BPN $(n=12)$. These experiments were also necessitated to address concerns that spurious labeling of terminals in the BPN may have resulted from spread of anterograde tracer into the entopenduncular nucleus, which also issues dense inputs into the ventral pons (Takada et al., 1994). FG injections targeting the BPN revealed a subpopulation of retrogradely labeled neurons in the medial aspect of this CeA (Fig. $8 D, E$ ), and this was observed reliably in every rat $(n=8)$ regardless of placement variability, excepting instances in which tracer placements were entirely caudal to pontine nuclei $(n=4)$. Also consistent with the foregoing anterograde tracing experiment, retrograde labeling in the CeA was exclusively ipsilateral. These data confirm a previous report (Mihailoff et al., 1989) and provide an anatomical basis for understanding the functional gating properties of CeA in auditory eyeblink conditioning.

\section{Discussion}

Inactivation of the CeA with muscimol severely impaired acquisition of dEBC (Fig. 1C,D). During subsequent training without infusions, the CeA inactivation group (session 6, criterion) showed an acquisition rate that was equivalent to the initial acquisition rate of the control group (sessions 1-5), which indicates a lack of savings in the CeA inactivation group. This finding demonstrates that the deficit in conditioning during the inactivation sessions was caused by impaired learning, not by impaired expression. However, it is important to note that the CeA inactivation group showed a higher percentage of CRs during acquisition than is typically seen with unpaired training $(\sim 10 \%)$, suggesting that there was a small amount of associative learning in this group during sessions $1-5$. The deficit in acquisition is consistent with previous studies that showed impaired acquisition of $\mathrm{dEBC}$ with lesions or muscimol inactivation of the amygdala (Lee and Kim, 2004; Blankenship et al., 2005; Ng and Freeman, 2014). These findings and those of the current study indicate that the amygdala plays a critical role in acquisition, but they do not indicate that the amygdala is essential for acquisition of eyeblink conditioning. Some of the previous studies have shown that animals with amygdala lesions will eventually acquire eyeblink conditioning with additional training (Weisz et al., 1992; Blankenship et al., 2005; Burhans and Schreurs, 2008). Moreover, animals decerebrated just rostral to the red nucleus can acquire eyeblink conditioning, indicating that the forebrain is not necessary (Lovick and Zbrozyna, 1975; Norman et al., 1977; Hesslow, 1994; Kotani et al. 2002). Thus, the amygdala modulates cerebellar learning mechanisms during eye- 

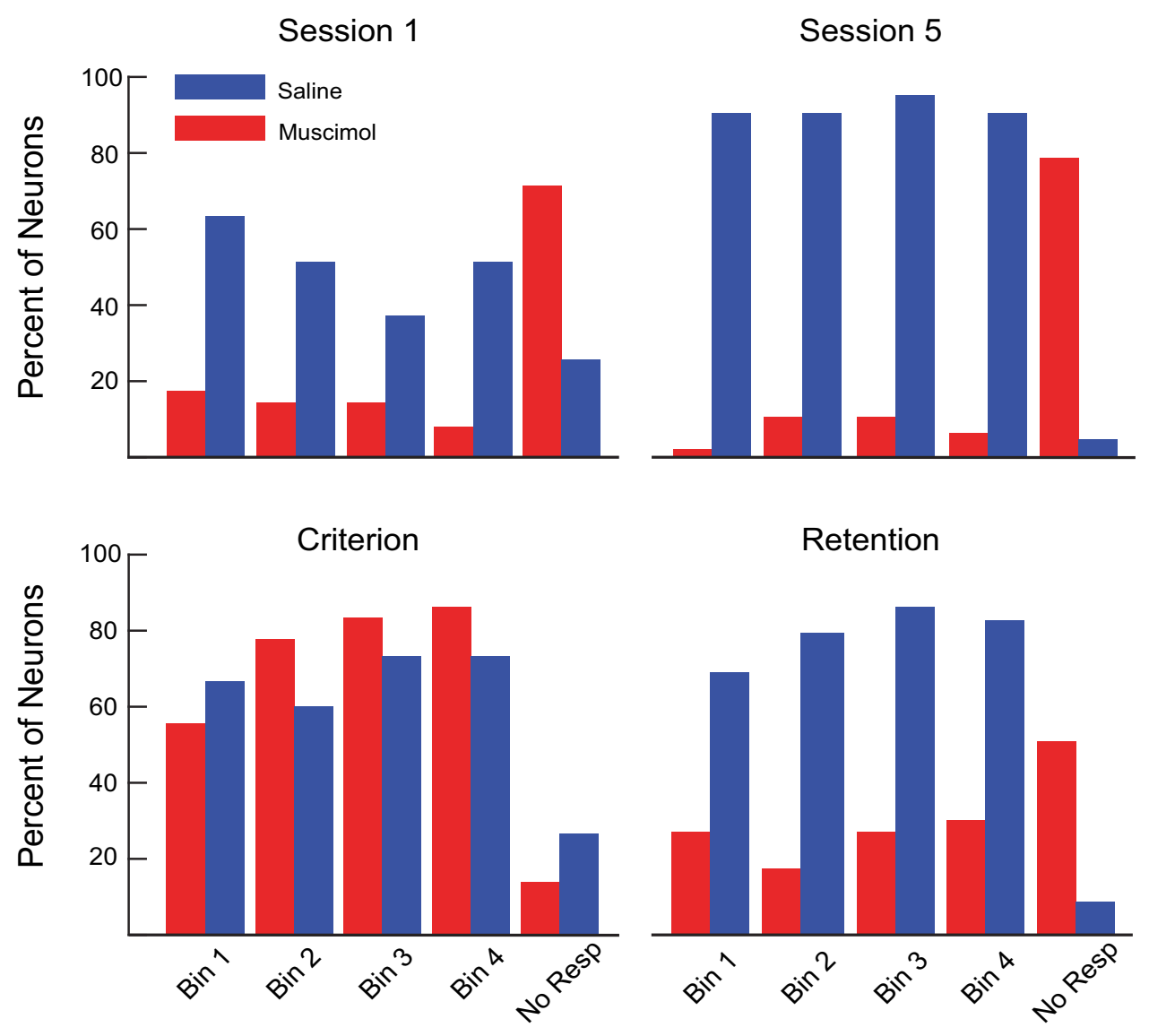

Figure 5. Percentage of AIN neurons with activity significantly above the pre-CS baseline period during the CS period (separated into $100 \mathrm{~ms}$ bins) during session 1 , session 5 , the criterion session, and the retention sessions. The majority of recorded neurons did not show a significant increase in activity during the CS period after muscimol infusions in sessions 1 and 5 . By the criterion session, the majority of neurons in both groups showed an increase in activity during the CS. During the retention sessions, muscimol infusions into the CeA decreased the percentage of neurons with increased activity during the CS in both groups. No Resp, Nonresponsive neurons.

blink conditioning. The deficit in the acquisition rate of eyeblink conditioning with amygdala lesions has supported a two-process theory of eyeblink conditioning in which rapidly developing plasticity in the amygdala results in defensive response CRs early in training and facilitates subsequent plasticity in the cerebellum resulting in the motor CR (Mowrer, 1947; Konorski, 1967; Thompson, 1987; Weisz et al., 1992; Mintz and Wang-Ninio, 2001; Taub and Mintz, 2010). As cerebellar learning develops, it is thought that the role of the amygdala diminishes (Lee and Kim, 2004; Magal and Mintz, 2014). However, retention of the CR was also severely impaired in the current study by CeA inactivation, indicating that the amygdala is playing a critical role in eyeblink conditioning after the motor CR is well established (Siegel et al., 2015). Based on these behavioral results, we hypothesize that the amygdala gates auditory input to the cerebellum during conditioning, and this sensory gating function plays a critical role during learning and retrieval. The sensory gating hypothesis is supported by our analyses of neuronal activity within the cerebellar AIN. Learning-related increases in neuronal firing within the AIN were abolished by CeA inactivation during acquisition and retention of eyeblink conditioning (Fig. $6 A, B, E, F$ ). CeA inactivation had no effect on baseline firing rates in the cerebellum, indicating that the reduction in firing rate was specific to CS-elicited activity. CeA inactivation substantially reduced the number of cerebellar neurons recruited during conditioning, and those neurons that did have a CS-evoked response had lower firing rates than in controls. Not only were learning-related increases in cerebellar activity inhibited for the first five sessions, but no cerebellar neuronal savings was noted in the inactivation group during session 6 (first session without muscimol infusions; Fig. 6C). After the cessation of CeA inactivation, there was a substantial increase in cerebellar neuronal responses to the $\mathrm{CS}$ in the $\mathrm{CeA}$ inactivation group, with no indication of a lingering deficit (Fig. 6D). After CRs and learningrelated neuronal activity were acquired, both were abolished by CeA inactivation (Fig. 6E). Thus, the influence of the amygdala on cerebellar learning mechanisms appears to be as strong during retention as it is during acquisition. These findings support the sensory gating hypothesis by showing that cerebellar neuronal responses to the CS are reversibly abolished by $\mathrm{CeA}$ inactivation.

A key part of the sensory gating hypothesis is that the CeA inactivation should inhibit sensory input to the cerebellum and not just affect learning-related increases in activity. Support for the CeA affecting sensory input to the cerebellum comes from a study (Taub and Mintz, 2010) that examined the effect of CeA inactivation on multiple-unit activity in the BPN with simultaneous CeA inactivation in anesthetized rats. This study found that amygdala inactivation reduced CS-elicited activity in the BPN during conditioning. In the current study, we further examined the effects of CeA inactivation on sensory input to the cerebellum by examining cerebellar neuronal responses to the CS within the first training session, before learning developed (Fig. 7). We found that CeA inactivation caused a deficit in shortlatency neuronal responses to the CS during the first session, as early as the first 10-trial block. Thus, the CeA has a substantial 
A

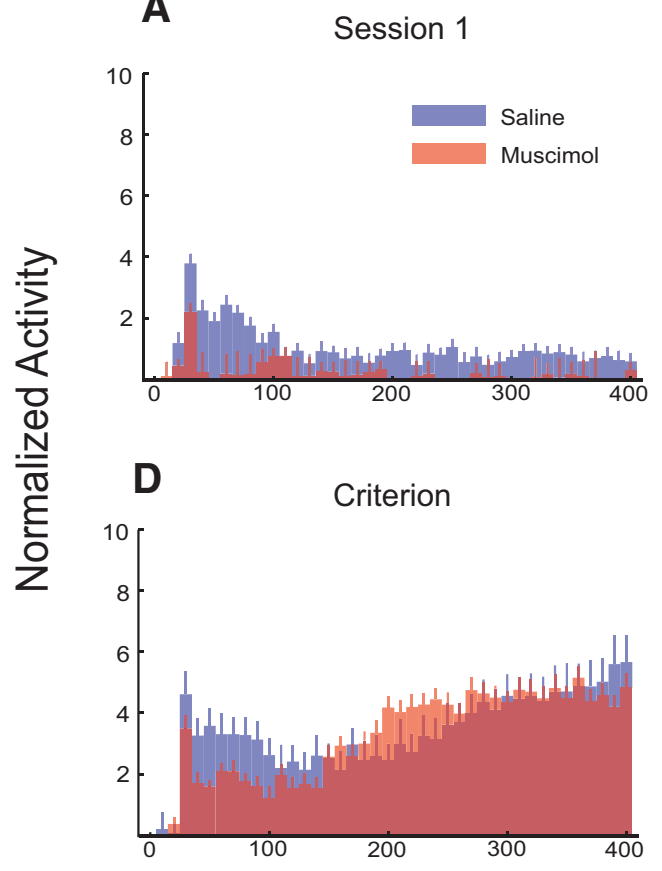

B

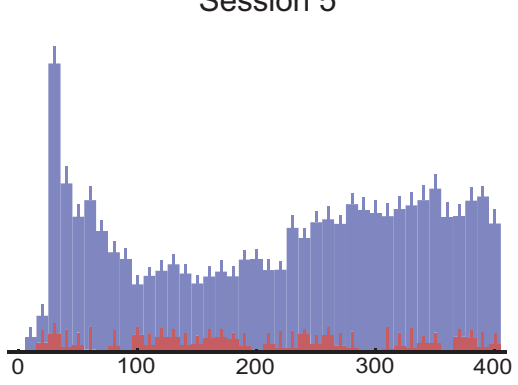

E

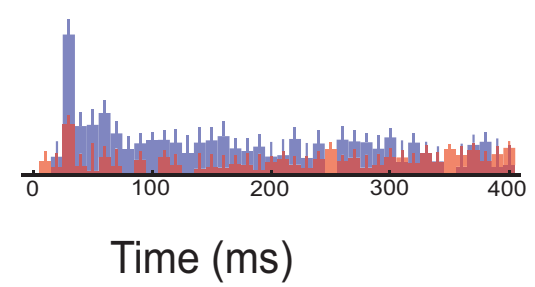

Muscimol Retention
C

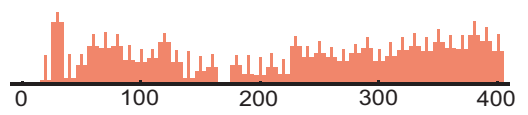

F

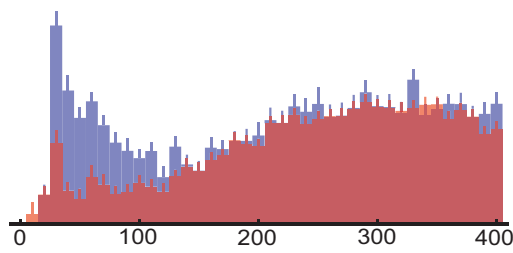

Session 6

Saline Retention

Figure 6. Mean \pm SE normalized neuronal activity (spikes per seconds) in the AIN in rats given saline or muscimol infusions into the CeA. $\boldsymbol{A}$, During session 1 , neuronal activity was greater in the saline group than in the muscimol group during the first 1010 -ms bins. $\boldsymbol{B}$, During session 5 , there was a substantial increase in the magnitude of neuronal firing during the CS relative to session 1 in the saline group but not in the muscimol group. C, Neuronal activity from the rats that received muscimol for sessions $1-5$ during session 6 did not show a substantial increase relative to session 5 , indicating the absence of neuronal savings. $\boldsymbol{D}$, During the criterion session, neuronal activity did not differ between the groups. $\boldsymbol{E}$, During the muscimol retention sessions, neuronal activity was severely suppressed during the $C S$ in both groups, but the saline group had greater short-latency activity than the muscimol group. $\boldsymbol{F}$, During the saline retention sessions, the group difference in neuronal activity was only evident in the short-latency response to the CS. Bar opacity is reduced to show group data overlap.
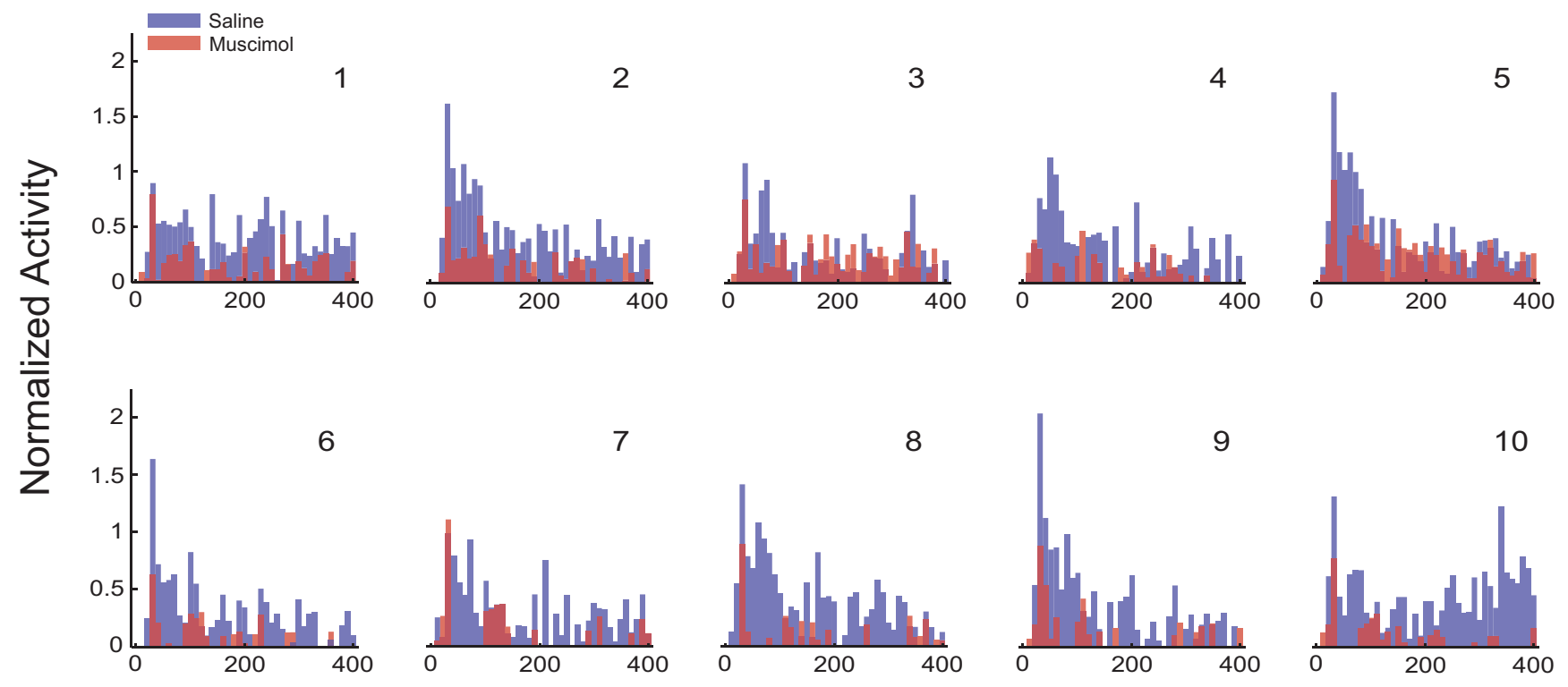

\section{Time (ms)}

Figure 7. Mean normalized neuronal activity (spikes per seconds) in the AIN in rats given saline or muscimol infusions into the CeA during session 1 broken down into 10-trial blocks. Neuronal activity in the saline group was greater than in the muscimol group as early as Block 1, suggesting that CeA inactivation affects cerebellar responses to the auditory CS before conditioning develops. Bar opacity is reduced to show group data overlap. 

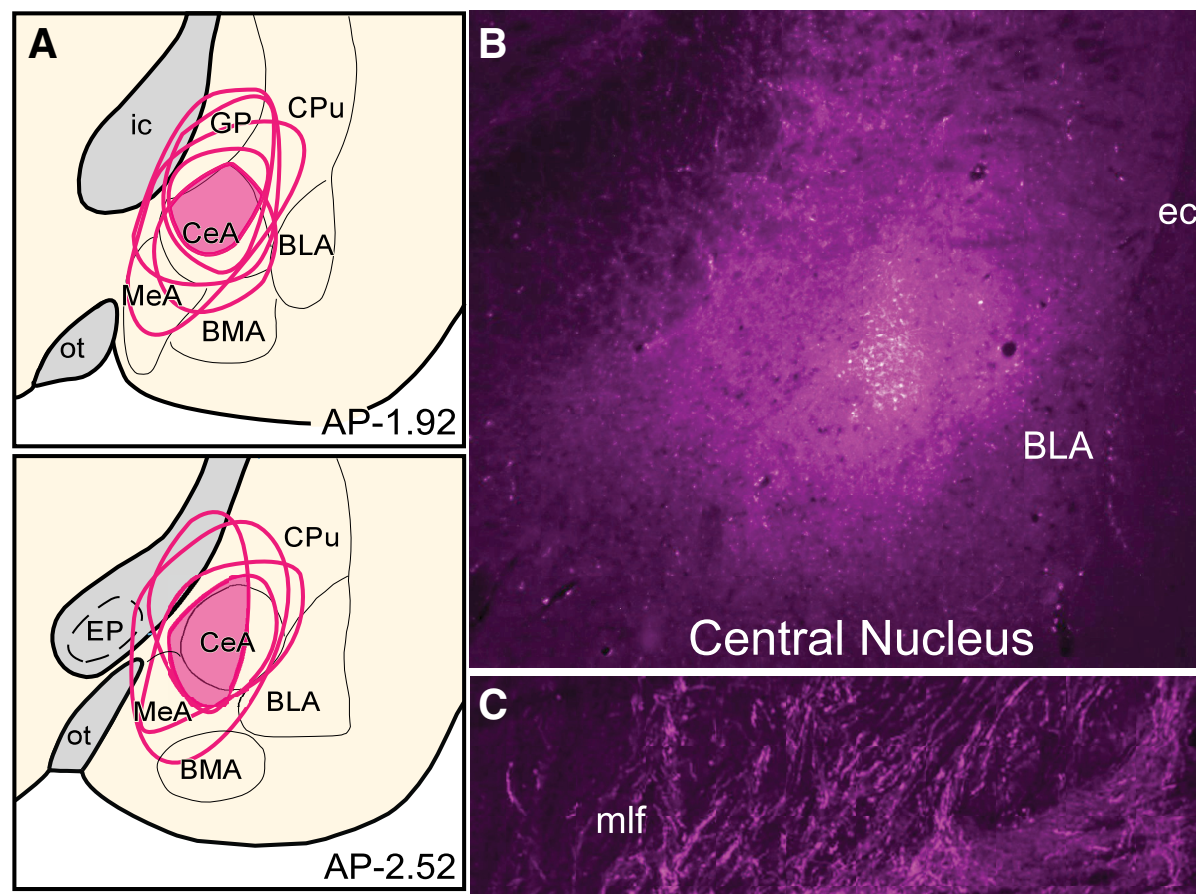

BLA

\section{ec}

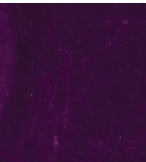


ditory CS pathway for eyeblink conditioning. A prominent component of the auditory CS pathway is the auditory thalamus, which includes the suprageniculate (SG), MGm, PIN, and neighboring medial auditory thalamic nuclei. These thalamic nuclei then project to the lateral BPN, which, in turn, project auditory input to the cerebellum (LeDoux et al., 1990; Shammah-Lagnado et al., 1996; Halverson and Freeman, 2010a; Fig. 8C). A study by Poremba and Gabriel (2001) found that rabbits given amygdala inactivation with muscimol during discriminative avoidance conditioning did not develop learning-related neuronal activity in the MGm, and learningrelated activity in the MGm did not develop after the cessation of inactivation. Therefore, the short-latency CS-elicited activity found in the current study might be driven by plasticity in the medial auditory thalamus. If this is the case, CeA inactivation might have had the same effect as in the Poremba and Gabriel study, that is, muscimol inactivation of the CeA during initial training may have blocked plasticity in the MATN and thereby blocked the development of shortlatency CS-elicited activity in the cerebellum. The mechanisms by which the amygdala transiently influences medial auditory thalamic plasticity are not known.

Axonal tract tracers were used to investigate whether the CeA could affect cerebellar learning via a direct projection to the CS pathway. (Mihailoff et al., 1989; Siegel et al., 2015). Robust anterograde labeling of axons and terminals were found in the ipsilateral BPN. Labeling was particularly strong in the lateral aspect of the BPN, which conveys auditory CS input to the cerebellum (Steinmetz et al., 1987; Campolattaro et al., 2008; Halverson and Freeman, 2010a). Recently, anterograde tracers have also revealed CeA efferents terminating in the lateral BPN in mice (Siegel et al., 2015). Retrograde neuronal labeling was also found in the CeA with tracer injections into the BPN in the current study. Thus, auditory CS information in the BPN could be gated directly by the CeA. However, it is also possible that CS input to the BPN is gated via multisynaptic pathways from the CeA to either the MGm or the periaqueductal gray (PAG). Projections from the CeA to the PAG are known to drive defense behaviors and analgesia and the PAG projects to the BPN (Paredes et al., 2000). The other multisynaptic pathway by which the CeA could influence $\mathrm{CS}$ input to the cerebellum is the $\mathrm{CeA} \rightarrow \mathrm{MGm} / \mathrm{SG} \rightarrow \mathrm{BPN}$ pathway. In this case, the CeA would gate auditory input to the PN by modulating activity in the MGm and SG. Additional studies are needed to determine the necessary pathway(s) for auditory eyeblink conditioning. This analysis will likely necessitate optogenetic approaches to selectively manipulate different projections of the CeA.

In conclusion, the behavioral and neuronal findings presented here indicate that cerebellar learning mechanisms are attenuated with CeA inactivation. Deficits in sensory-evoked and learning-related cerebellar neuronal activity suggest a sensory gating function for amygdala-cerebellum interactions. The CeA may gate auditory input to the cerebellum through direct projections to the $\mathrm{BPN}$, a putative $\mathrm{CeA} \rightarrow \mathrm{MGm} / \mathrm{SG} \rightarrow$ BPN pathway, or the CeA $\rightarrow$ PAG $\rightarrow$ BPN pathway. This sensory on-gating mechanism might be an attention-like mechanism (for review, see Gallagher and Holland, 1994) that increases sensory input to the cerebellum for stimuli that have acquired significance as signals for important events such as the periorbital stimulation US in the current study. In contrast to previous theories of amygdala-cerebellum interactions, the sensory gating hypothesis posits that the gating mechanism continues to be necessary for retrieval of cerebellar memory after learning is well established.

\section{References}

Blankenship MR, Huckfeldt R, Steinmetz JJ, Steinmetz JE (2005) The effects of amygdala lesions on hippocampal activity and classical eyeblink conditioning in rats. Brain Res 1035:120-130. CrossRef Medline

Brodal P, Bjaalie JG (1992) Organization of the pontine nuclei. Neurosci Res 13:83-118. CrossRef Medline

Burhans LB, Schreurs BG (2008) Inactivation of the central nucleus of the amygdala abolishes conditioning-specific reflex modification of the rabbit (Oryctolagus cuniculus) nictitating membrane response and delays classical conditioning. Behav Neurosci 122:75-88. CrossRef Medline

Campolattaro MM, Freeman JH (2008) Eyeblink conditioning in 12-dayold rats using pontine stimulation as the conditioned stimulus. Proc Natl Acad Sci U S A 105:8120-8123. CrossRef Medline

Campolattaro MM, Freeman JH (2009) Cerebellar inactivation impairs cross modal savings of eyeblink conditioning. Behav Neurosci 123: 292-302. CrossRef Medline

Campolattaro MM, Halverson HE, Freeman JH (2007) Medial auditory thalamic stimulation as a conditioned stimulus for eyeblink conditioning in rats. Learn Mem 14:152-159. CrossRef Medline

Freeman JH Jr, Nicholson DA (1999) Neuronal activity in the cerebellar interpositus and lateral pontine nuclei during inhibitory classical conditioning of the eyeblink response. Brain Res 833:225-233. CrossRef Medline

Freeman JH, Steinmetz AB (2011) Neural circuitry and plasticity mechanisms underlying delay eyeblink conditioning. Learn Mem 18:666-677. CrossRef Medline

Freeman JH, Halverson HE, Hubbard EM (2007) Inferior colliculus lesions impair eyeblink conditioning in rats. Learn Mem 14:842-846. CrossRef Medline

Gallagher M, Holland PC (1994) The amygdala complex: multiple roles in associative learning and attention. Proc Natl Acad Sci U S A 91: 11771-11776. CrossRef Medline

Halverson HE, Freeman JH (2006) Medial auditory thalamic nuclei are necessary for eyeblink conditioning. Behav Neurosci 120:880-887. CrossRef Medline

Halverson HE, Freeman JH (2010a) Medial auditory thalamic input to the lateral pontine nuclei is necessary for auditory eyeblink conditioning. Neurobiol Learn Mem 93:92-98. CrossRef Medline

Halverson HE, Freeman JH (2010b) Ventral lateral geniculate input to the medial pons is necessary for visual eyeblink conditioning in rats. Learn Mem 17:80-85. CrossRef Medline

Halverson HE, Poremba A, Freeman JH (2008) Medial auditory thalamus inactivation prevents acquisition and retention of eyeblink conditioning. Learn Mem 15:532-538. CrossRef Medline

Halverson HE, Poremba A, Freeman JH (2015) Medial auditory thalamus is necessary for acquisition and retention of eyeblink conditioning to cochlear nucleus stimulation. Learn Mem 22:258-266. CrossRef Medline

Harris KD, Henze DA, Csicsvari J, Hirase H, Buzsáki G (2000) Accuracy of tetrode spike separation as determined by simultaneous intracellular and extracellular measurements. J Neurophysiol 84:401-414. Medline

Hesslow G (1994) Inhibition of classically conditioned eyeblink responses by stimulation of the cerebellar cortex in the decerebrate cat. J Physiol 476:245-256. CrossRef Medline

Hopkins DA (1975) Amygdalotegmental projections in the rat, cat and rhesus monkey. Neurosci Lett 1:263-270. CrossRef Medline

Hopkins DA, Holstege G (1978) Amygdaloid projections to the mesencephalon, pons and medulla oblongata in the cat. Exp Brain Res 32:529-547. Medline

Kleim JA, Freeman JH Jr, Bruneau R, Nolan BC, Cooper NR, Zook A, Walters D (2002) Synapse formation is associated with memory storage in the cerebellum. Proc Natl Acad Sci U S A 99:13228-13231. CrossRef Medline

Konorski J (1967) Integrative activity of the brain; an interdisciplinary approach. Chicago: University of Chicago.

Kotani S, Kawahara S, Kirino Y (2002) Classical eyeblink conditioning in decerebrate guinea pigs. Eur J Neurosci 15:1267-1270. CrossRef Medline

Krettek JE, Price JL (1978) Amygdaloid projections to subcortical structures within the basal forebrain and brainstem in the rat and cat. J Comp Neurol 178:225-254. CrossRef Medline

LeDoux JE, Ruggiero DA, Reis DJ (1985) Projections to the subcortical fore- 
brain from anatomically defined regions of the medial geniculate body in the rat. J Comp Neurol 242:182-213. CrossRef Medline

LeDoux JE, Farb C, Ruggiero DA (1990) Topographic organization of neurons in the acoustic thalamus that project to the amygdala. J Neurosci 10:1043-1054. Medline

Lee T, Kim JJ (2004) Differential effects of cerebellar, amygdalar, and hippocampal lesions on classical eyeblink conditioning in rats. J Neurosci 24:3242-3250. CrossRef Medline

Lovick TA, Zbrozyna AW (1975) Responses to corneal stimulation in the trigeminal nuclei. J Physiol 245:81P-82P. Medline

Magal A, Mintz M (2014) Inhibition of the amygdala central nucleus by stimulation of cerebellar output in rats: a putative mechanism for extinction of the conditioned fear response. Eur J Neurosci 40:3548-3555. CrossRef Medline

Mihailoff GA (1995) Orthograde axonal transport studies of projections from the zona incerta and pretectum to the basilar pontine nuclei in the rat. J Comp Neurol 360:301-318. CrossRef Medline

Mihailoff GA, Kosinski RJ, Azizi SA, Border BG (1989) Survey of noncorti$\mathrm{cal}$ afferent projections to the basilar pontine nuclei: a retrograde tracing study in the rat. J Comp Neurol 282:617-643. CrossRef Medline

Mintz M, Wang-Ninio Y (2001) Two-stage theory of conditioning: involvement of the cerebellum and the amygdala. Brain Res 897:150-156. CrossRef Medline

Mowrer OH (1947) On the dual nature of learning — a re-interpretation of "conditioning" and "problem-solving." Harvard Educ Rev 17:102-148.

Ng KH, Freeman JH (2012) Developmental changes in medial auditory thalamic contributions to associative motor learning. J Neurosci 32: 6841-6850. CrossRef Medline

$\mathrm{Ng} \mathrm{KH}$, Freeman JH (2014) Amygdala inactivation impairs eyeblink conditioning in developing rats. Dev Psychobiol 56:999-1007. CrossRef Medline

Norman RJ, Buchwald JS, Villablanca JR (1977) Classical conditioning with auditory discrimination of the eye blink in decerebrate cats. Science 196: 551-553. CrossRef Medline

Ottersen OP, Ben-Ari Y (1979) Afferent connections to the amygdaloid complex of the rat and cat. I. Projections from the thalamus. J Comp Neurol 187:401-424. CrossRef Medline

Paredes J, Winters RW, Schneiderman N, McCabe PM (2000) Afferents to the central nucleus of the amygdala and functional subdivisions of the periaqueductal gray: neuroanatomical substrates or affective behavior. Brain Res 887:157-173. CrossRef Medline

Paxinos G, Watson C (2007) The rat brain in stereotaxic coordinates, Ed 6. Amsterdam: Academic/Elsevier.

Poldrack RA, Packard MG (2003) Competition among multiple memory systems: converging evidence from animal and human brain studies. Neuropsychologia 41:245-251. CrossRef Medline

Poremba A, Gabriel M (2001) Amygdalar efferents initiate auditory thalamic discriminative training-induced neuronal activity. J Neurosci 21: 270-278. Medline

Price JL, Amaral DG (1981) An autoradiographic study of the projections of the central nucleus of the monkey amygdala. J Neurosci 1:1242-1259. Medline

Prokasy WF (1987) A perspective on the acquisition of skeletal responses employing the pavlovian paradigm. In: Classical conditioning, Ed 3 (Gormezano I, Thompson RF, Prokasy WF, eds), pp 287-318. Hillsdale, NJ: Erlbaum.
Reiner A, Veenman CL, Medina L, Jiao Y, Del Mar N, Honig MG (2000) Pathway tracing using biotinylated dextran amines. J Neurosci Methods 103:23-37. CrossRef Medline

Sawchenko P, Cunningham ET Jr, Mortrud MT, Pfeiffer SW, Gerfen CR (1990) Phaseolus vulgaris-leucoagglutanin (PHA-L) anterograde axonal transport technique. Methods Neurosci 3:247-260. CrossRef

Schmitzer-Torbert N, Jackson J, Henze D, Harris K, Redish AD (2005) Quantitative measures of cluster quality for use in extracellular recordings. Neuroscience 131:1-11. CrossRef Medline

Schmued LC, Fallon JH (1986) Fluoro-gold: a new fluorescent retrograde axonal tracer with numerous unique properties. Brain Res 377:147-154. CrossRef Medline

Shammah-Lagnado SJ, Alheid GF, Heimer L (1996) Efferent connections of the caudal part of the globus pallidus in the rat. J Comp Neurol 376: 489-507. CrossRef Medline

Shinoda Y, Sugihara I, Wu HS, Sugiuchi Y (2000) The entire trajectory of single climbing and mossy fibers in the cerebellar nuclei and cortex. Prog Brain Res 124:173-186. CrossRef Medline

Shu SY, Ju G, Fan LZ (1988) The glucose oxidase-DAB-nickel method in peroxidase histochemistry of the nervous system. Neurosci Lett 85: 169-171. CrossRef Medline

Siegel JJ, Taylor W, Gray R, Kalmbach B, Zemelman BV, Desai NS, Johnston D, Chitwood RA (2015) Trace eyeblink conditioning in mice is dependent upon the dorsal medial prefrontal cortex, cerebellum, and amygdala: behavioral characterization and functional circuitry. eNeuro 2:1-29. CrossRef Medline

Steinmetz AB, Freeman JH (2014) Localization of the cerebellar cortical zone mediating acquisition of eyeblink conditioning in rats. Neurobiol Learn Mem 114:148-154. CrossRef Medline

Steinmetz JE, Sengelaub DR (1992) Possible conditioned stimulus pathway for classical eyelid conditioning in rabbits. I. Anatomical evidence for direct projections from the pontine nuclei to the cerebellar interpositus nucleus. Behav Neural Biol 57:103-115. CrossRef Medline

Steinmetz JE, Logan CG, Rosen DJ, Thompson JK, Lavond DG, Thompson RF (1987) Initial localization of the acoustic conditioned stimulus projection system to the cerebellum essential for classical eyelid conditioning. Proc Natl Acad Sci U S A 84:3531-3535. CrossRef Medline

Takada M, Tokuno H, Ikai Y, Mizuno N (1994) Direct projections from the entopeduncular nucleus to the lower brainstem in the rat. J Comp Neurol 342:409-429. CrossRef Medline

Taub AH, Mintz M (2010) Amygdala conditioning modulates sensory input to the cerebellum. Neurobiol Learn Mem 94:521-529. CrossRef Medline

Thompson RF (1987) Neuronal substrates of discrete, defensive conditioned reflexes. Conditioned fear states and their interactions in the rabbit. In: Classical conditioning, Ed 3 (Gormezano I, Thompson RF, Prokasy WF, eds), pp 371-399. Hillsdale, NJ: Erlbaum.

Tracy JA, Thompson JK, Krupa DJ, Thompson RF (1998) Evidence of plasticity in the pontocerebellar conditioned stimulus pathway during classical conditioning of the eyeblink response in the rabbit. Behav Neurosci 112:267-285. CrossRef Medline

Weisz DJ, Harden DG, Xiang Z (1992) Effects of amygdala lesions on reflex facilitation and conditioned response acquisition during nictitating membrane response conditioning in rabbit. Behav Neurosci 106:262273. CrossRef Medline 